\title{
"A IMPORTÂNCIA DOS OBJETIVOS OPERACIONAIS NO ENSINO DE GRADUAÇAO EM ENFERMAGEM"
}

\author{
$\begin{array}{rr}\text { Lygia Paim } & * \\ \text { Luiza Aparecida Texeira Costa } & * * \\ \text { Solange Maria Ramos } & * * \\ & \text { Sono Taira }\end{array} *$
}

I - INTRODUÇAOO

Considerações Preliminares

Os currículos dos cursos de Graduação em Enfermagem ao serem elaborados exigem sejam feitas, entre outras, as seguintes considerações: - qual o nivel de competência do enfermeiro, que atividades o caracterizam como tal, quals os padrões mínimos de desempenho aceitáveis do profissional que se deseja preparar diante das necessidades reais de saúde do país. Certamente, essas preocupações vão servir de base à determinação dos objetivos que se deseja alcançar através do desenvolvimento curricular, e que deverão ser avaliados para garantir a qualidade do ensino e possibilitar um desempenho definido em termos de comportamentos adquiridos durante o curso. Constitui-se, portanto, etapa fundamental dos programas de ensino, a determinação dos objetivos operacionais e paralelamente a determinação dos tipos de avaliação que possam assegurar que os mesmos poderão ser atingidos.

Segundo Lobo e Jouval Jr., "a soma dos comportamentos que os alunos deverão exibir ao realizar com proficiência todas as ex-

* Autor e relator - Professor da Escola de Enfermagem da UFRJ.

* * Co-autores - Professores da Escola de Enfermagem da UFRJ.

*** Co-autor — Professor da Escola de Enfermagem de Rib. Preto - USP. 
periências instrucionais delineadas para o curso, constitui o objetivo terminal desse curso, poderemos afirmar que a eficiência do programa educacional é indicada pela diferença entre o comportamento desejado e efetivamente exibido pelos alunos ao terminarem o curso. Evidentemente que a eficácia será tanto maior quanto menor a diferença observada".

Gagné (1965) valoriza a execução e propõe o ensino centrado na mudança de comportamento, portanto, a didática centrada na realização.

Mudança de comportamento e realização dentro dos objetivos educacionais de enfermagem significam condutas finais tanto na área cognitiva, como afetiva e psicomotora de modo que forme o estudante como pessoa, ser social e favoreça a incorporação de um sistema de valores para uma concepção do mundo, para atuar como agente de mudanças, para reconhecer a situação social e de saúde de seu país e, sobretudo, para compreender a importância das suas relações como as demais pessoas e da sua participação no processo contínuo de ensino e aprendizagem.

Cabe às Escolas a responsabilidade de selecionar as disciplinas que, além do currículo mínimo, formarão o currículo pleno permitindo ao estudante um acervo de conhecimentos e comportamentos finais condizentes com o papel do enfermeiro na sociedade, diante da situaçâo de saúde do país, destacando, nestes comportamentos um caráter realista e exequível, a partir da seleção das experiências educativas que a escola oferece, porque este aspecto são fundamentais no processo de desenvolvimento da enfermagem.

Segundo o Seminário sobre Ensino de Enfermagem (OPAS-OMS1972), as funções do enfermeiro, estão ligadas às atividades que os mesmos desempenham nos serviços de saúde, e se resumem em 5 (cinco), quais sejam:

- atuar como participante no processo da Assistência de Enfermagem;

- atuar como educadora;

- atuar como participante em Pesquisa;

- administrar serviços de Enfermagem;

- participar das Associações de Classe.

Entretanto, dentre essas funções, segundo a opinião dos autores desse trabalho, algumas parecem ser mais solicitadas que outras, razão porque alguns objetivos precisam ser mais destacados que outros, não apenas visando delinear os comportamentos terminais mas também uma hierrarquização de valores que pode ser traduzida, à partir da seleção de objetivos para os programas de ensino do Curso de Graduação em Enfermagem, os quais devem também 
ser expressos sob a forma de transformações ou aquisições na maneira de pensar, sentir e atuar dos educandos. Cabe esclarecer que, segundo essa perspectiva, a determinação de objetivos deverá obedecer a uma diretriz tangenciada na realidade de saúde do país, em confronto com as características da profissão de enfermeiro.

$\mathrm{Na}$ fase de avaliação, portanto, os padrões de comportamento desejáveis na atuação do enfermeiro, em termos de realização, devem ser considerados e podem ser verificados, mediante as atividades habitualmente exercidas pelo profissional, na realidade em que opera.

Segundo os autores, a determinação desses objetivos em cada disciplina, deveria estar condicionada a um conjunto de experiências curriculares que situasse $o$ aluno diante das funções próprias do enfermeiro dentro de um princípio de realidade. Por conseguin. te, os comportamentos finais dos educandos precisariam corresponder às atividades que são exercidas pelos enfermeiros; assim sendo, os cursos precisariam oferecer aos alunos oportunidades para execução de atividades coerentes com essas funções, e nesse caso, o desempenho de cada aluno terá necessariamente que corresponder ao indicado como o mínimo aceitável.

\section{O Problema e as Hipóteses Formuladas}

Dentre as responsabilidades dos professores dos cursos de graduação em enfermagem, uma das maiores, se não a maior delas, é a determinação dos objetivos com a conseqüente tarefa de operacionalizá-los.

A experiência no Campo de Prática, resultante de sucessivos encontros entre enfermeiros de escolas e enfermeiros de serviço em hospitais de ensino, tem levado ambos os grupos, e mais especificamente o de docentes, à preocupações relativas ao enfermeiro que se deseja formar. Tais preocupações têm sido por vezes verbalizada através de questões que nos leva a necessárias reflexões as quais, por sua vez, nos compele à busca de dados que forneçam alguns achados e se constituam motivo de novos estudos e descobertos. Algumas dessas questões são do conhecimento de todos os que exercem a enfermagem:

- Os objetivos do Curso de Graduação têm sido traçados à luz da realidade existente nos Campos de Prática?

- Os objetivos considerados importantes para os enfermeiros de escolas têm sido os mesmos considerados importantes pelos enfermeiros de serviço? 
- Os comportamentos finais dos alunos do Curso de Graduação têm correspondido à expectativa dos enfermeiros em exercício nos serviços de Saúde? ou seja, têm sido aqueles realmente importantes diante das funções mais solicitadas nos Serviços de Saúde?

Face a essas questões e na tentativa de encontrar resposta a algumas delas está o propósito deste trabalho, para o que foram formuladas as seguintes hipóteses:

- A definição dos objetivos operacionais no ensino de Graduação em Enfermagem é importante tanto para as Escolas como para os Serviços.

- Os comportamentos esperados pelos professores após o desenvolvimento dos Programas de Ensino das Escolas de Enfermagem coincidem com os esperados pelo pessoal de Enfermagem dos Serviços de Saúde.

- Há objetivos operacionais no ensino de Graduação em Enfermagem que são mais evidenciados que outros, o que estabelece uma ordem de prioridades que coincide com as funções desejáveis para o enfermeiro, mas não coincide com as solicitações dos serviços.

\section{II - REVISAO DA LITERATURA}

Alcântara (1960), em um estudo sobre "Revisão do Currículo: - Princípios Gerais", tratou dos objetivos que a Escola deve atingir referindo-se a padrões de comportamento; que experiências educativas devem ser oferecidas aos estudantes para a consecução desses objetivos; como organizar tais experiências e como verificar se as objetivos estão sendo alcançados. Tratou ainda da formulação de objeivos de uma Escola de Enfermagem, envolvendo a participação de outros grupos interessados, além do Corpo Docente.

RIVERA, (1961), tratou da importância e papel dos objetivos no trabalho docente, destacando que este é o ponto de partida obrigatório de todo o trabalho docente, que os objetivos devem ser dellmitados e precisos, funcionais e tradutores de resultados práticos a serem atingidos em cada etapa do trabalho.

CARVALHO, (1967), apresentou um estudo sobre finalidade e objetivos do curso de enfermagem. Preconizou como essencial a determinação antecipada de que tipo de assistência o enfermeiro deve estar preparado para planejar, executar ou orientar e supervisionar o pessoal de enfermagem no exercício dessas funções e ao término 
do curso possa exercer atividades administrativas nas Instituições de Saúde; considerou que há atitudes profissionais típicas sem as quais o enfermeiro não poderá desempenhar bem as suas funções; c que o corpo docente deve considerar todos esses aspectos quando definir os objetivos para formação do profissional, ressaltando as características de realidade e exequibilidade como ponto de partida para a seleção das experiências educativas oferecidas ao estudante de enfermagem.

RIBEIRO, (1969), fez considerações sobre o tradicionalismo dos cursos de graduação, mostrando a necessidade de estudos sobre um amplo conceito do papel do enfermeiro na sociedade e sobre o tipo de profissional de que o país necessita, recomendando a reformulação dos currículos das Escolas de Enfermagem baseados em pesquisas educacionais para identificar as atividades de enfermagem realizadas pelo enfermeiro e que irão permitir uma reflormulação de currículo mais realista e que responda às nossas necessidades.

Em 1970, a mesma autora tratou das novas tendências no ensino e na prática da enfermagem considerando esses dois termos como correlativos de um mesmo problema muito interligado, que exige cooperação mútua e contínua entre educadores e pessoal dos Serviços de Enfermagem. Uma vez que o objetivo à assistência integral de enfermagem é responsabilidade tanto das Escolas como dos Serviços de Enfermagem.

Em 1971, em seminário organizado pela OPAS-OMS, sobre ensino de enfermagem a nível universitário foi abordado o tema "objetivos educacionais" e estes foram definidos como objetivos que "devem ser expressos em condutas finais na área cognitiva, afetiva e psicomotora" e que para estruturá-los uma escola de enfermagem precisa considerar a interrelação dos objetivos gerais e as funções que se espera sejam exercidas pelo futuro profissional. Considerou-se ainda que na formulação dos objetivos deve-se ter como base a conduta final antecipada, isto é, a formação de profissionais capazes de desempenhar as funções derivadas da análise da população; da demanda dos serviços de enfermagem e das características do exercício proflissional voltadas para o futuro.

COE (1967), no artigo "A relativa importância dos objetivos educacionais selecionados em enfermagem", considerada a maior responsabilidade do corpo docente a determinação de objetivos, lembrando que, além disso, é preciso fazer opções atendendo a uma escala de prioridades a fim de estabelecer quais desses objetivos devem ser mais destacados em função do exercício profissional. 


\section{III - METODOLOGIA ADOTADA}

\section{Seleção da Amostra}

Foram estudados dois grupos de enfermeiros - professores de escolas de enfermagem e enfermeiros de serviços de saúde da Guanabara. Cada grupo foi constituído por 50 (cinqüenta) enfermeiros. Considerou-se que cada um dos respondentes era basicamente um enfermeiro; deixou-se de procurar identificar outras variáveis, tais como, o quantum de experiência em enfermagem, a área de especialidade, ou os antecedentes educacionais do enfermeiro.

Professores de escolas: foi organizada uma lista com o nome de todos os professores de cada uma das escolas de enfermagem e selecionados aqueles que ministravam disciplinas de enfermagem, que ofereciam experiência de campo; desses, foram selecionados como respondentes apenas os que se encontravam em exercício na ocasião 50 (cinqüenta) professores.

Enfermeiros de serviços de saúde: foi organizada uma lista de todos os serviços de saúde que serviam de Campos Clínicos às escolas de enfermagem e a seleção desses campos foi feita à base de sorteio, estabelecendo-se que os 7 (sete) sorteados seriam incluídos neste estudo. $O$ critério para a seleção dos enfermeiros respondentes foi que os mesmos exercessem suas atividades em setores do serviço de saúde em que os estudantes de enfermagem desenvolvessem atividades teórico-práticas. O conjunto dos 7 (sete) serviços de saúde, obedecido o critério enunciado, apresentou um total de 50 (cinqüenta) enfermeiros.

\section{- Procedimento}

Coleta de dados: Um questionário foi aplicado aos dois grupos com o propósito de que cada um dos respondentes enumerasse quais os comportamentos finais que deveriam estar incorporados pelos recém-graduados ao término do Curso de Graduação.

O mé todo permitiu que os respondentes registrassem alguns atributos individuais correspondentes às seguintes informações: - escola em que se graduou; graduada há quantos anos; ocupação; tempo em que exerce a ocupação referida; instituição em que trabalha; idade cronológica. (Tabela 1).

A enumeração dos 25 (vinte e cinco) itens considerados os comportamentos finais mais importantes segundo os dois grupos está relacionada na Tabela II. 
A base dessas informações, foi constituído um grupo de trabalho do qual fizeram parte 2 (dois) professores de escolas de enfermagem e 2 (dois) enfermeiros de serviços de saúde com a finalidade de reduzir a lista de 25 (vinte e cinco) comportamentos, a uma outra de apenas io (dez) itens. Esses 10 (dez) itens, já arrolados em ordem alfabética foram utilizados para construir um formulário enviado aos dois gruitem um número de 1 (um) a 10 (dez), o que corresponderia à ordem de prioridade* atribuída a cada item. (Tabela III).

\section{IV - RESULTADOS}

As tabelas de números IV, V, VI, VII, VIII, IX, X, XI, XII, XIII, demonstram numericamente e em percentual as opiniões dos dois grupos quanto à ordem de prioridade atribuída a cada item do formulário.

$\mathrm{Na}$ tabela IV e no Gráfico 1 - pode-se observar a distribuição cla freqüência dos 2 (dois) grupos quanto às suas opiniões a respeito da importância de "administrar serviços' de enfermagem" como comportamento final do Curso de Graduação.

Quanto aos professores: nenhum professor valorizou este comportamento como prioritário; $26 \%$ deram o último lugar de importância a este comportamento. $74 \%$ atribuíram lugares de 2 a 9 , isto é, consideraram um ojetivo importante, mas não prioritário, sendo que a maior freqüência entre estes $74 \%$ se encontra nos lugares de importância 5 a 6 , constituindo-se $26 \%$. Deduz-se, portanto, que "administrar serviços de enfermagem" tem uma importância relativa para os professores, assumindo uma pasição de média importância entre as 10 comportamentos.

Quanto aos enfermeiros: ao contrário dos professores, $22 \%$ atribuíram valor prioritário ao item "administrar serviços de enfermagem". Outros $42 \%$ classificaram este comportamento entre o $2.0^{\circ}$ e o 4. lugares de importância. Logo, $64 \%$ valorizaram-no, colocando-o nos $1 .^{\circ}$ lugares de importância. 30\% dos enfermeiros colocaram este comportamento entre o $5 .^{\circ}$ e o $10^{\circ}$ lugares. Deduz-se, que "administrar serviços de enfermagem" significa um comportamento dos mais importante para o enfermeiro. A tabela $\mathrm{V}$ e gráfico 2 - demonstram

$\begin{array}{ll}\text { Critério }- \text { Escala de Valores } \\ * 1=\text { prioritário } & 2 \text { a } 4 \text { - importante } \\ & 5 \text { a } 6 \text { - importância média } \\ 10=\text { de menor valor } & \text { 7 a } 9=\text { pequena importância }\end{array}$


a distribuição de freqüência para o lugar de importância atribuído ao comportamento - "avaliar a qualidade da assistência de enfermagem".

Quanto aos professores: $12 \%$ deles atribuíram a este comportamento o sétimo lugar de importância; $44 \%$ atribuiram importância entre 4 e 6 , enquanto que os outros $44 \%$ estiveram divididos entre os 3 primeiros $(26 \%)$ e 3 últimos lugares $(18 \%)$.

Deduz-se que este é um comportamento importante, mas que o mesmo não é prioritário; está entre os de média importância consi-

Quanto aos enfermeiros: na distribuição $50 \%$ ocupam a faixa do centro (de 4 a 8), Os demais distribuem-se: nos 3 primeiros lugares, $44 \%$; e nos dois últimos lugares apenas $6 \%$. Ambos os grupos valorizam este comportamento como importante, isto é, valor de qüência dos dois grupos, relativa ao item 00-3 - "Colaborar em pesquisas na área da saúde".

Quanto aos professores - nenhum considerou este item prioritário; apenas $8 \%$ consideraram-no importante; $22 \%$ colocaram-no em posição de média importância e $70 \%$ atribuiram pequena importância ao mesmo, dos quais, $30 \%$ consideraram-no o de menor valor.

Quanto aos enfermeiros: distribuição semelhante ocorreu com os enfermeiros. $24 \%$ atribuiram valor entre 2 e 4, isto é, consideraram importante este item, $8 \%$ consideraram-no de média importância, enquanto que $68 \%$ atribuiram pequena importância, dos quais, $26 \%$ consideraram o comportamento como de menor valor.

Deduz-se portanto, que tanto proflessores quanto enfermeiros não valorizam a Pesquisa como comportamento dos mais importantes, sendo que os enfermeiros atribuiram um pouco mais de importância a este item que os professores.

A tabela VII e o Gráfico 4 - mostram a distribuição de freqüência de respostas-opiniōes quanto ao comportamento: Oo-4 - "Comunicar-se efetivamente como profissional".

Para os professores - apenas $4 \%$ consideram-no como prioritário; $26 \%$ consideraram-no importante; $36 \%$, de média importância e $34 \%$ de pequena importância, dos quais, $10 \%$ atribuíram o menor valor a este item.

Para os enfermeiros: $6 \%$ consideraram-no prioritário; $40 \%$ consideram-no importante; $22 \%$, de média importância e $32 \%$ de pequena importância, dos quais, $8 \%$ atribuíram-lhe o menor valor.

Logo, este item ocupou lugar mais importante na opinião dos enfermeiros que o grupo de professores.

A tabela VIII e o Gráfico 5, referem-se à distribuição de freqüênde cuidados de enfermagem". 
Para os professores: $6 \%$ consideraram-no prioritário; $70 \%$, importante; $16 \%$, de valor médio; $8 \%$, de pequena importância, sendo que nenhum professor o considerou de menor valor.

Para os enfermeiros: $2 \%$ consideraram-no prioritário; $2 \%$, importante; $48 \%$, de média importância; $24 \%$ de pequena importância e $6 \%$ como o de menor valor.

Pode-se deduzir que professores e enfermeiros valorizam a elaboração de planos escritos de enfermagem; entretanto, este valor apresenta-se em niveis distintos de importância para os dois grupos, recaindo o maior percentual, na distribuição de professores, na faixa de importante, enquanto que no grupo de enfermeiros o maior percentual se encontra na faixa de média importância.

A tabela IX e o Grálico 6, relativos ao item 00-6 - "exercitar-se na profissão de acordo com as responsabilidades éticas e legais de enfermagem", apresentou os seguintes dados:

Quanto aos professores, este item ocupou valor prioritário para $8 \%$; foi considerado importante para $34 \%$ deste grupo; atribuíram-lhe média importância $14 \%$; e pequena importância $44 \%$, dos quais $6 \%$ consideraram-nos de menor valor.

Quanto aos enfermeiros: como no grupo dos professores, $8 \%$ atribuíram valor prioritário e $34 \%$ consideraram-no importante; $30 \%$ atribuíram-lhe média importância, sendo que nenhum enfermeiro conferiu o menor valor a este item.

A distribuição entre os dois grupos foi relativamente semelhante, destacando-se apenas que o grupo de professores, ainda que em pequeno percentual, situou este item como o de menor valor, o que não ocorreu com o grupo de enfermeiros, que não atingiu esse extremo.

A tabela $\mathrm{X}$ e o Gráfico 7, relativos ao item Oo-7 - “interpretar a profissão junto à equipe de saúde, liderando a equipe de enfermagem", evidenciam que:

Quanto aos professores: $4 \%$ classificaram-nos como prioritário, enquanto $32 \%$ classificaram-no como importante; $22 \%$ atribuiram-1he média importância; outros $42 \%$ classificaram-no como de pequena importância, dos quais, $4 \%$ consideraram-no de menor valor.

Quanto aos enfermeiros: $12 \%$ deste grupo conferiram a este item c valor prioritário; $16 \%$ consideraram-no importante; outros $16 \%$ situaram-no como tendo importância média; e $56 \%$ de pequena importância, dos quais $6 \%$ conferiram-lhe o menor valor.

Deduz-se daí que há discordância apenas no grau de importância atribuído a este item pelos dois grupos.

A tabela XI e o Gráfico 8 -, relativos ao item 00-8 "participar das atividades da comunidade (oferecer, utilizar $e$ indicar recursos)", mostram que: 
Quanto aos professores: nenhum classificou este item como prioritário; $22 \%$ classificaram-no como importante; $30 \%$ conferiram-lhe média importância; e outros $48 \%$, pequena importância, dos quais $18 \%$ conferiram-lhe o menor valor.

Quanto aos enfermeiros: negaram prioridade a este comportamento, distribuíndo-se: $8 \%$ deles consideraram-no importante; $10 \%$ classificaram-no entre os lugares de média importância; $68 \%$ restantes acharam que este seria um comportamento de pequena importância, enquanto $14 \%$ consideraram-no o item de menor valor.

Deduz-se que, em ambos os grupos este comportamento não ocupou destaque nos primeiros lugares, e em nenhum dos dois grupos conseguiu atingir a prioridade.

Entretanto, pode-se assinalar que os professores valorizam mais este comportamento que os enfermeiros, cuja maior concentração (mais da metade) esteve entre 7 e 9, correspondendo a um comportamento de pequena importância.

A tabela XII e o Gráfico 9 - referem-se ao item 00-9 - "prestar cuidados diretos e pacientes demonstrando competência e habilidade técnica", evidenciam:

Para os professores: $14 \%$ consideram que este é o comportamento mais importante, ocupando valor prioritário. Os demais $26 \%$ distribuiram-se da seguinte forma: $16 \%$ opinaram que este é um comportamento importante e $10 \%$ afirmaram ser este um comportamento de pequena importância. Nota-se que nenhum professor considerou este item de menor valor.

Para os enfermeiros: $42 \%$ situaram este item como prioritário. Os demais situaram-se na seguinte distribuição: $28 \%$ entre 2 e 4; consideraram, portanto, um comportamento importante; $6 \%$ consideraram-no de média importância e $14 \%$ consideraram-no de pequena importância e $10 \%$ opinaram ser este o comportamento de menor valor.

Deduz-se que os profesores estão mais concentrados em suas opiniões a respeito do que é mals importante para eles e sobretudo do lugar de importância que este comportamento ocupa; enquanto os enfermeiros estão menos coesos em opinar sobre a importância ciesse item expressando opiniões que se diluem quando distribuídos entre todos os valores da escala, do máximo, ao mínimo, perdendio parte da expressividade sobre $o$ assunto.

Admite-se, entretanto, que ambos, de modo geral, são acordes quanto à afirmação de que este é um comportamento importante.

A tabela XIII e o Gráfico 10 - referem-se ao item 00-10 "Planejar, executar e avaliar programas de treinamento de enfermagem", informam que: 
Para os professores: $4 \%$ admitiram que este comportamento ocupa lugar de importância prioritária; $16 \%$ optaram pela posição entre 2 e 4; isto significa que este é um comportamento importante; $20 \%$ afirmaram ser este um comportamento de média importância, enquanto que os demais $60 \%$ situaram-no como comportamento de pequena importância, dos quais $4 \%$ atribuiram a este item o menor valor.

Para os enfermeiros: $4 \%$ consideram que este é um comportamento prioritário; $26 \%$ opinaram ser este um item importante; $22 \%$ atribuiram-no média importância; $28 \%$ afirmaram ser este um item de pequena importância, enquanto que os $20 \%$ restantes consideraram-no o item de menor valor.

Deduz-se que, para os dois grupos, este é um comportamento de pouca importância e que, portanto, ocupa os últimos lugares, dentro da escala prevista.

A Média Ponderada das Opiniões dos Dois Grupos.

Da análise das tabelas pode-se calcular, atribuindo peso a esses itens, a média ponderada de cada um deles, conforme se pode ler na Tabela XIV.

Analisando comparativamente as médias apuradas representativas do grupo de enfermeiros e do grupo de professores em cada um dos itens (comportamentos finais), pode-se afirmar que há uma diferença entre alguns deles e forte semelhança em outros. Se forem organizadas as médias ponderadas em ordem decrescente (da maior média ponderal para a menor média ponderal), tanto no grupo de professores como no de enfermeiros, poder-se-á admitir e analisar uma ordem de importância sugeridas segundo a média de opiniões apurada para cada um dos grupos, como se lê na Tabela XV.

A tabela XVI refere-se à coincidência ou não coincidência do lugar de importância atribuído a cada comportamento, considerando-se a média ponderada, organizada em ordem decrescente, obtida de cada um dos grupos, diante dos (dez) itens propostos.

Pode-se deduzir que há coincidência de opinião entre os dois grupos quanto ao lugar de importância para cada um dos seguintes comportamentos: 
Ordem coincidente de Item Objetivo Operacional (comportamento final) prioridade

O0-9 Prestar cuidados diretos a paciente, com competência e habilidade técnica

1. ${ }^{\circ}$ lugar

Oo-2 Avaliar a qualidade da assistência de enfermagem

3..$^{\text {lugar }}$

Oo-10 Planejar, executar e avaliar programas de treinamento de pessoal de enfermagem

8.0 lugar

Conseqüentemente, deduz-se que não há coincidência quanto ao lugar de importância para os demais comportamentos.

\section{V - INTERPRETAÇĀO DE DADOS}

\section{0-1 - Administrar Serviços de Enf'ermagem}

O percentual significado de enfermeiros que identificaram esse comportamento como dos mais importantes para o seu grupo, pode traduzir uma necessidade de revisão dos objetivos do currículo do Ensino de Graduação, a luz de uma realidade dos Serviços de Saúde baseados numa das funções do enfermeiro. Ao mesmo tempo é preciso atentar para a "situação de fato" que vem influenciando de grande modo as atividades do enfermeiro no sentido de aumentar a tendência de distanciá-lo daquelas atividades que o ligam diretamente ao paciente.

Por outro lado, os professores situaram-se em posição oposto quanto ao valor desse comportamento. Configurou-se o maior percentual no último dos lugares de importância para a função de administrar, substituindo Administrar por Elaborar Planos Escritos de Cuidados de Enfermagem, provavelmente em função de aproximar o enfermeiro de atividades que mais propriamente o caracterizem como tal. 


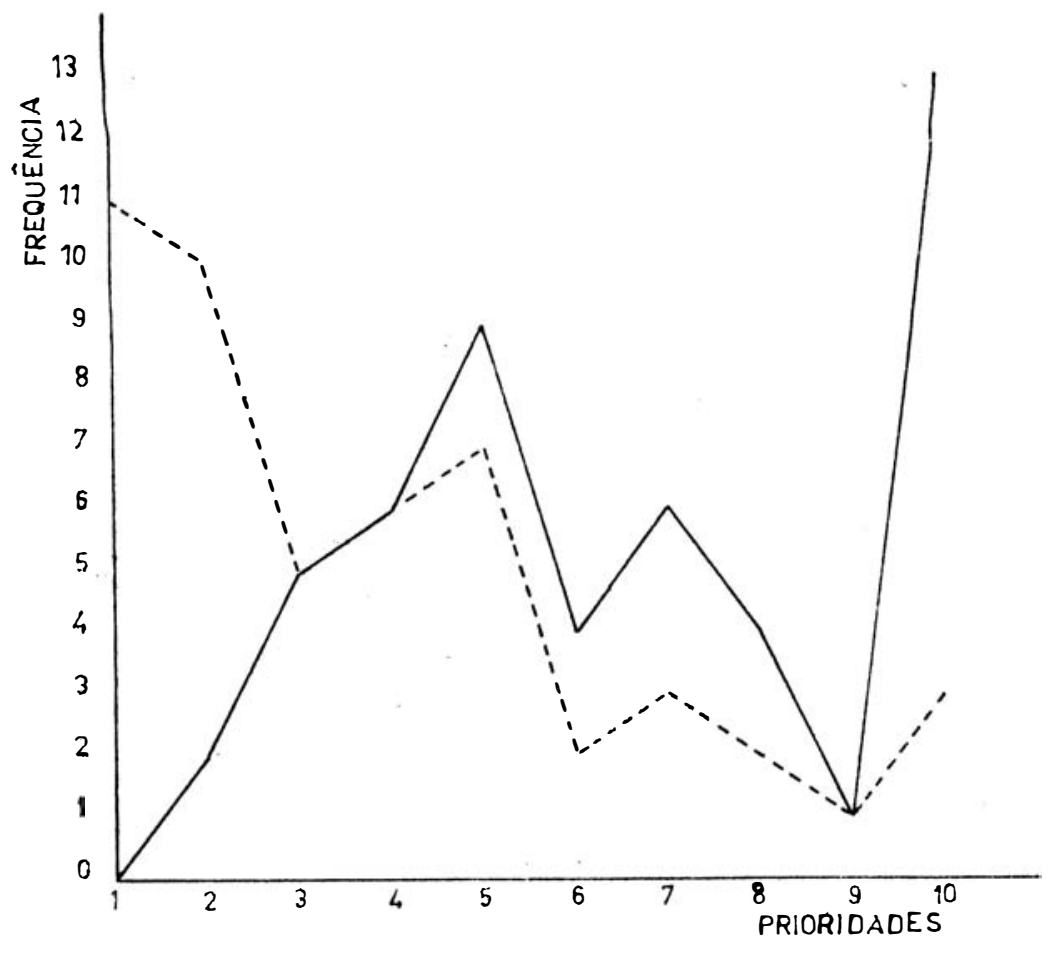

001-ADMINISTRAR SERVIÇOS DE ENFERMAGEM

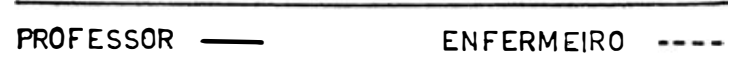

00-2 - Avaliar a Assistência de Enfermagem

Os Valores atribuídos pelos dois grupos a esse item traduzem um alto senso de responsabilidade quanto à constante preocupação de melhorar a qualidade do cuidado de enfermagem e de divulgar, promover a profissão através da elevação das condições de atenção que se pode oferecer ao paciente. A relação guardada entre a opinião dos dois grupos pode siginificar que ambos estão sentindo que, só através da avaliação contínua, pode-se desenvolver e elevar os padrões de cuidados ao paciente, e possivelmente ambos têm-se encontrado em situação de realizar essa avaliação constantemente, para encontrar dados comparativos na evolução da assistência de enfermagem. 


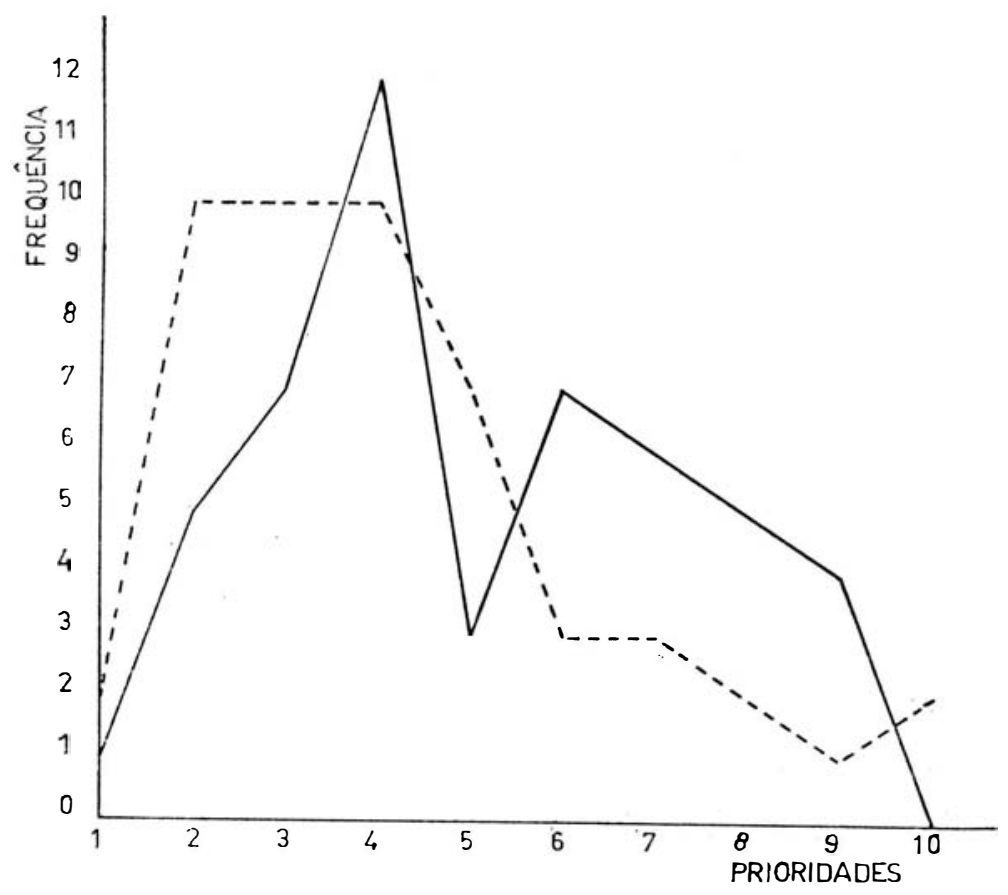

002- AVALIAR A QUALIDADE DA ASSISTENCIA DE ENF ERMAGEM

\section{0-3 - Colaborar em Pesquisas na Área da Saúde}

Os elevados percentuais, tanto de professores como de enfermiros que atribuíram última importância para este item, parecem traduzir a inexperiência e até certo ponto a falta de preparo para a realização de atividades dessa natureza. Ademais, pode-se admitir que o grupo de enfermeiros somente agora começa a familiarizar-se com a realização de investigações, passivelmente em razão das dificuldades e limitações oferecidas pelas "situações de fato" tanto nos Serviços de Saúde como nas Escolas. 


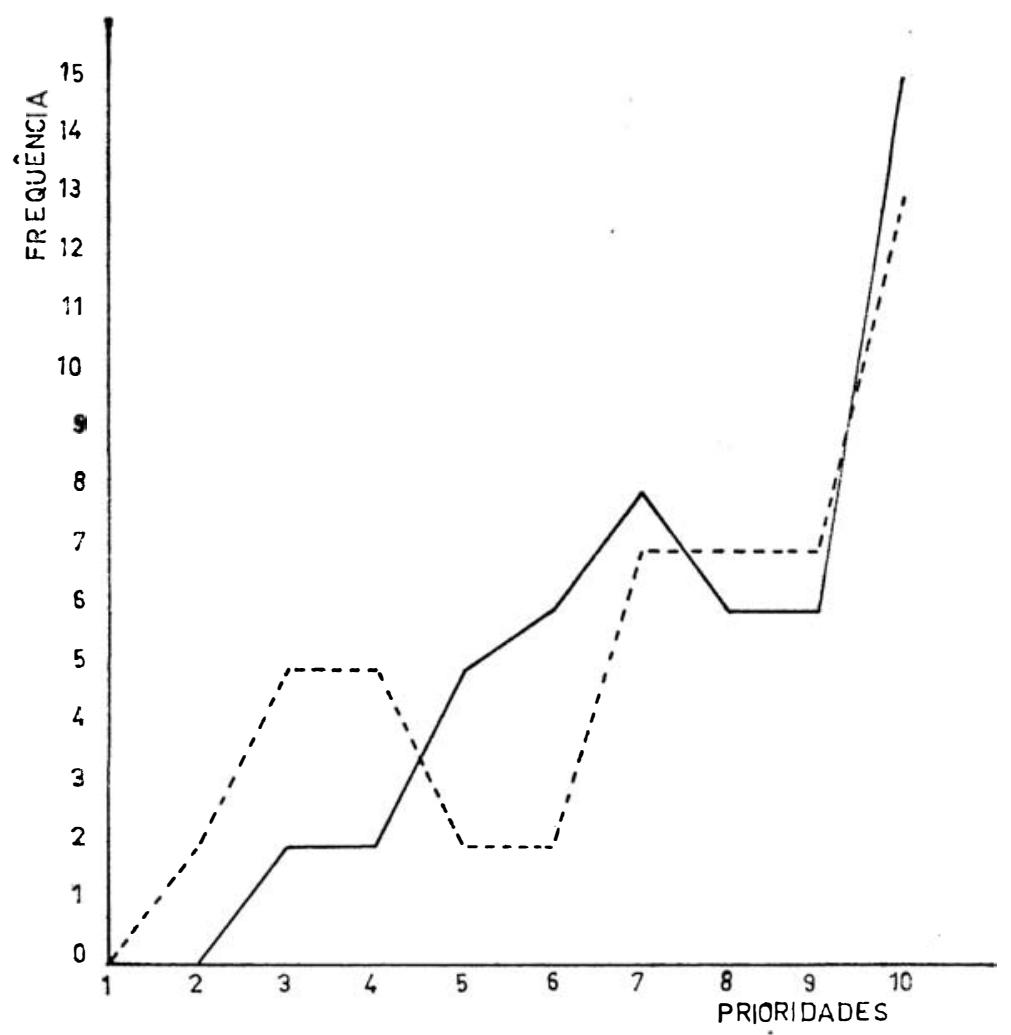

D03- colaborar em pesquisas na área da saúde

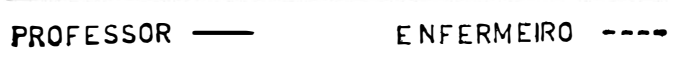

00-4 - Comunicar-se efetivamente como profissional

Os percentuais estiveram distribuídos em todas as ordens de importância para este comportamento. Parece que este comportamento em termos gerais obteve mais alta classificação entre os enfermeiros, entretanto, a valorização e/ou desvalorização desse item possivelmente deve estar ligada a um comportamento tão evidentemente necessário que estava implícito em cada um dos demais itens, segundo comentários escritos de alguns respondentes.

Por outro lado, pode-se perceber como se ressentem os hospitais e escolas de melhor qualidade de relacionamento verbal, escrito e não verbal; parece ter havido nesse item uma distribuição expressiva 
tanto para os primeiros como para os últimos lugares, não firmando posição quanto à concentração de opiniões em determinado valor. Essa posição de média importância parece se refletir atualmente na prática, isto é, os valores ligados a esses tipos de comunicação, embora sejam sempre ressaltados verbalmente, nem sempre parecem ser utilizados adequadamente.

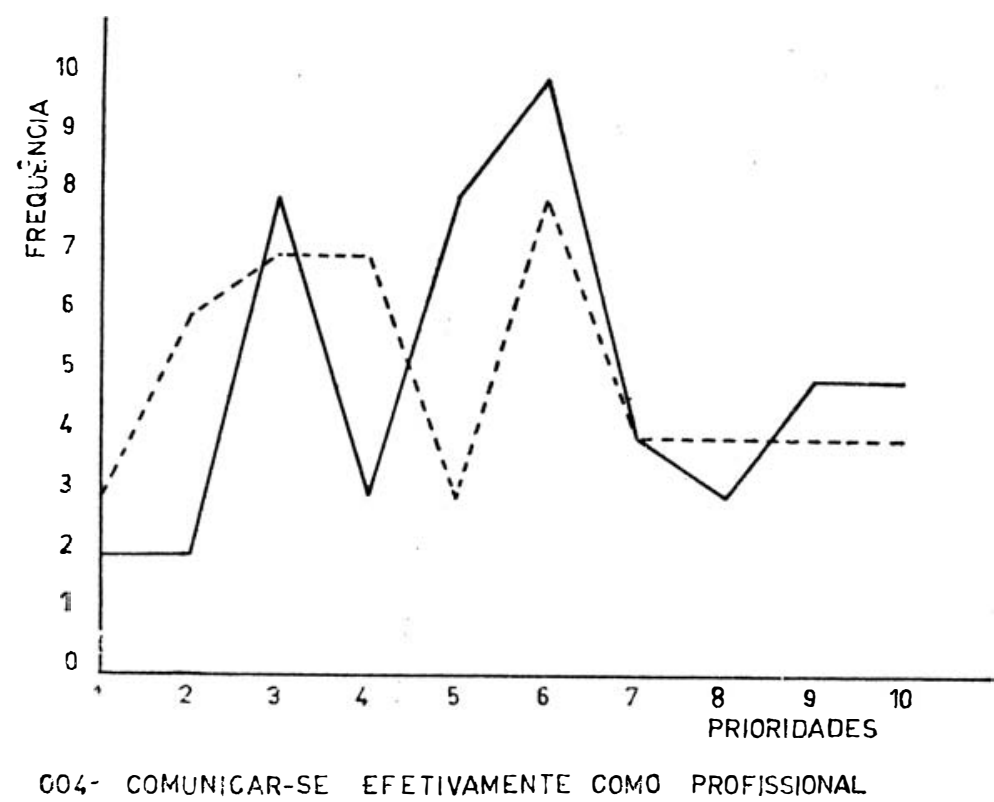

PROFESSOR

ENFERMEIT: $\quad-\cdots$

00-5 - Elaborar Planos Escritos de Cuidados de Enfermagem

A importância representada de forma significante no percentual de respostas dos professores quanto à valorização desse comportamento $(75 \%)$, parecem expressar a necessidade da documentação de uma atividade específica do enfermeiro, ao tempo em que reflete a preocupação dos mesmos pela aplicação do método científico nessas mesmas atividades e demonstra de forma intensiva os sentimentos e percepções desses mesmos professores quanto à responsabilidade dos enfermeiros na atenção direta ao paciente.

Ainda que menos intensamente, mas em elevado percentual, os enfermeiros também situam este comportamento como dos mais im- 


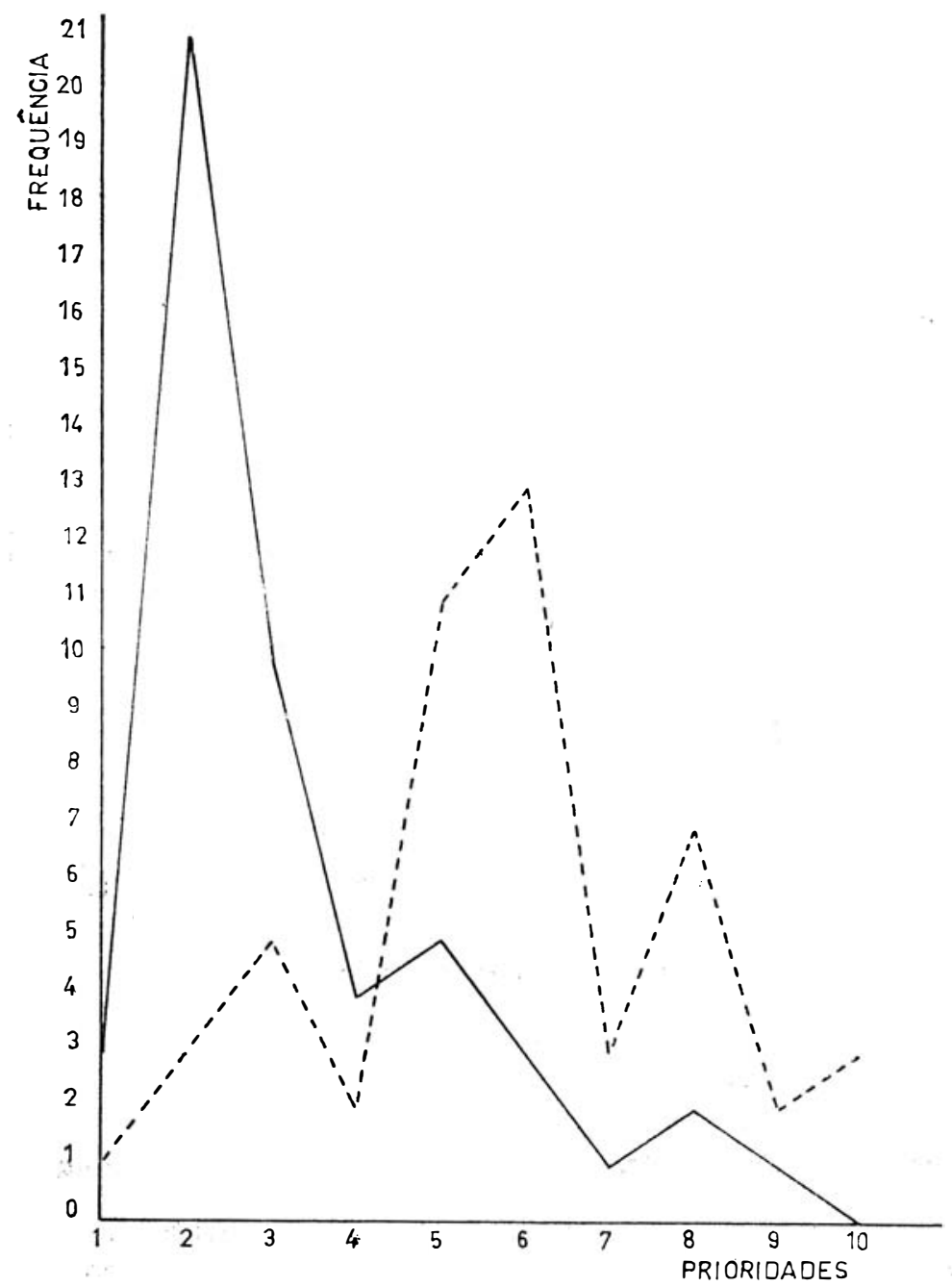

005- ELABORAR PLANOS ESCRITOS DE CUIDADOS DE ENFERMAGEM

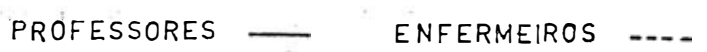


portantes. Possiveimente a diferença de distribuição, não caracterizando os dois grupos como reconhecedores do item como da maior importância, reside no fato de que as escolas vêm ensinando e os Serviços de Saúde não vêm dispondo de recursos para elaboração desses planos escritos.

A escassez de pessoal em serviço, outras atividades, vêm afas:tando o enfermeiro da atividade que ele próprio considera mais importante, qual seja, o cuidado direto ao pacente, conseqüentemente a elaboração de planos escritos desses cuidados têm sido muitas vezes também deixada de lado. A ausência de recursos humanos e materiais não deve estar permitindo ao enfermeiro a realização de todas as suas tarefas, mesmo aquelas que ele teria que dispor numa escala de valores como as mais importantes. A base dos resultados apresentados nesse item, presume-se que a falta de utilização desses planos deve ter levado os enfermeiros a classificá-lo como um item de média importância.

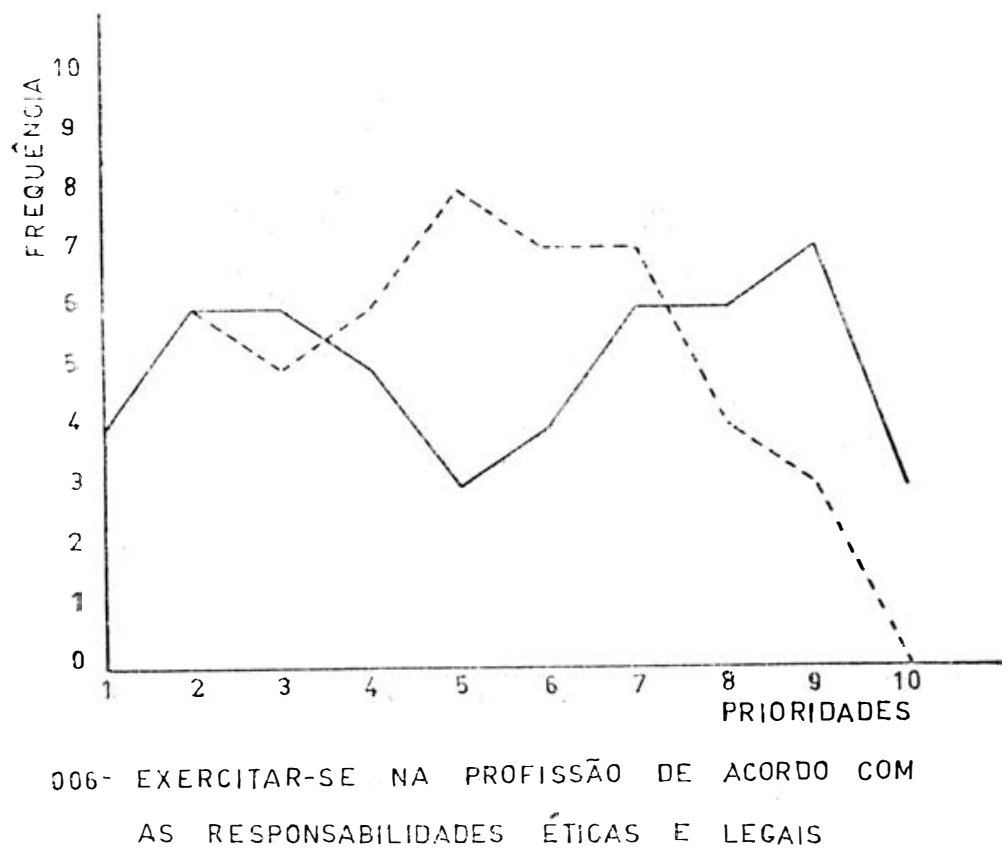


00-6 - Exercitar-se na profissão de acordo com as responsabilidades éticas e legais da enfermagem.

Não houve grande concentração de opiniões em determinado grau de importância, o que equivale dizer que os professores quanto a este assunto não parecem ter opinião firmada e coesa. Quanto aos enfermeiros pode-se considerar significativo que nenhum deles achou que este comportamento teria o último lugar de importância.

A ausência de definições de atribuições bem como o delegar e o assumir outras tarefas, provavelmente, têm trazido maiores conseqüências mais para o grupo de enfermeiros em serviço que para os professores de Escolas, e possivelmente houve essa influência nas respostas do grupo de enfermeiros, o que já os identifica como um grupo mais coeso em opinião quanto ao valor atribuído a esse assunto. Entretanto quando consideradas as médias ponderadas a classificação ocupa diferença de apenas um lugar de importância a mais que o outro grupo.

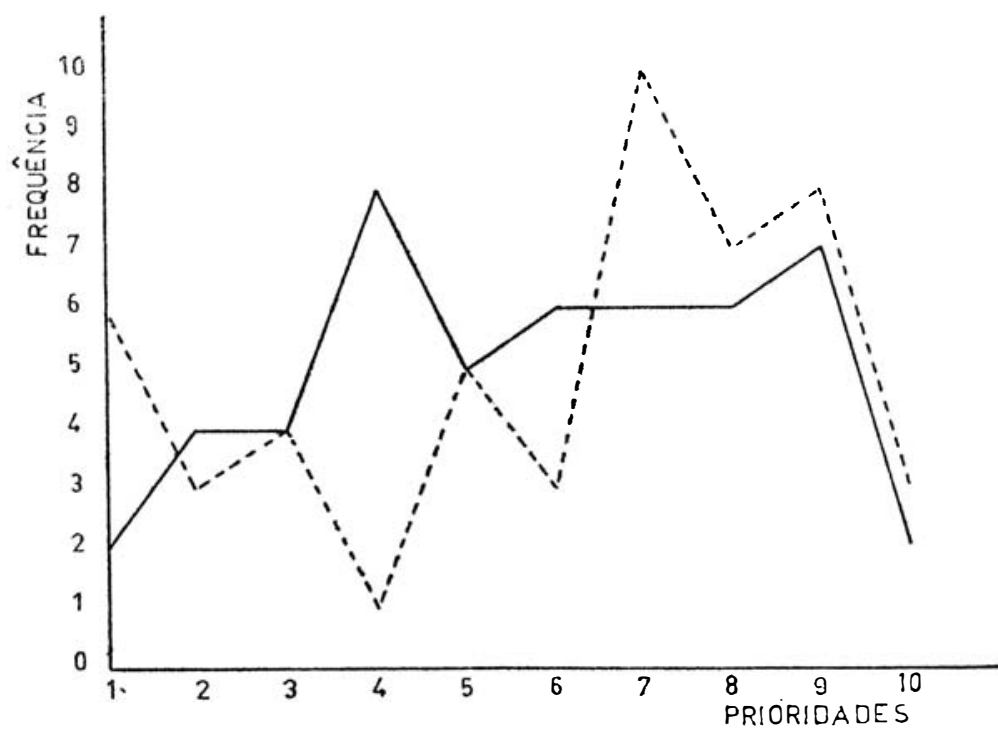

007- INTERPRETAR A PROFISSĀO JUNTO À EQUIPE DE SAÜDE LIDERANDO A EQUIPE DE ENFERMAGEM 
0o-7 - "Interpretar a profissão junto à equipe de saúde liderando a equipe de enfermagem".

Foi situado no grupo de professores guardando distribuição percentual relativamente semelhante à dos enfermeiros. Parece, ao verificar os dados, que esta questão, como a de comunicar-se não obteve grande expressividade de posição entre os dois grupos; considerando um comportamento que depende não só de informações e oportunidades de prática, mas também de potencialidade para torná-las em capacidades, este item parece ter sido francamente expressivo de um erforço e uma conscientização dos 2 (dois) grupos quanto à garantia de manutenção do desempenho do papel de líder que o enfermeiro ocupa na equipe de enfermagem, e, especificamente, do papel de coordenador das atividades da equipe de saúde, em função do paciente. Em ordem de prioridades este item guardou semelhança de classificação entre os dois grupos, com diferença 1 (um) entre as colocações.

00-8 - "Participar das atividades da Comunidade" (oferecer, utilizar e indicar recursos da Comunidade).

Em ambos os grupos, poucos valorizaram este comportamento como dos primeiros lugares de importância, entretanto, os professores valorizaram mais que os enfermeiros. A distribuição mostra que para os enfermeiros, com opinião bastante coesa entre eles, este é um comportamento que ocupa os últimos lugares de importância, o que parece indicar que os enfermeiros, nos Serviços de Saúde, não têm participado dos problemas da Comunidade. Na média de opinióes, nos dois grupos este é o comportamento que ocupa um dos últimos lugares de importância. 


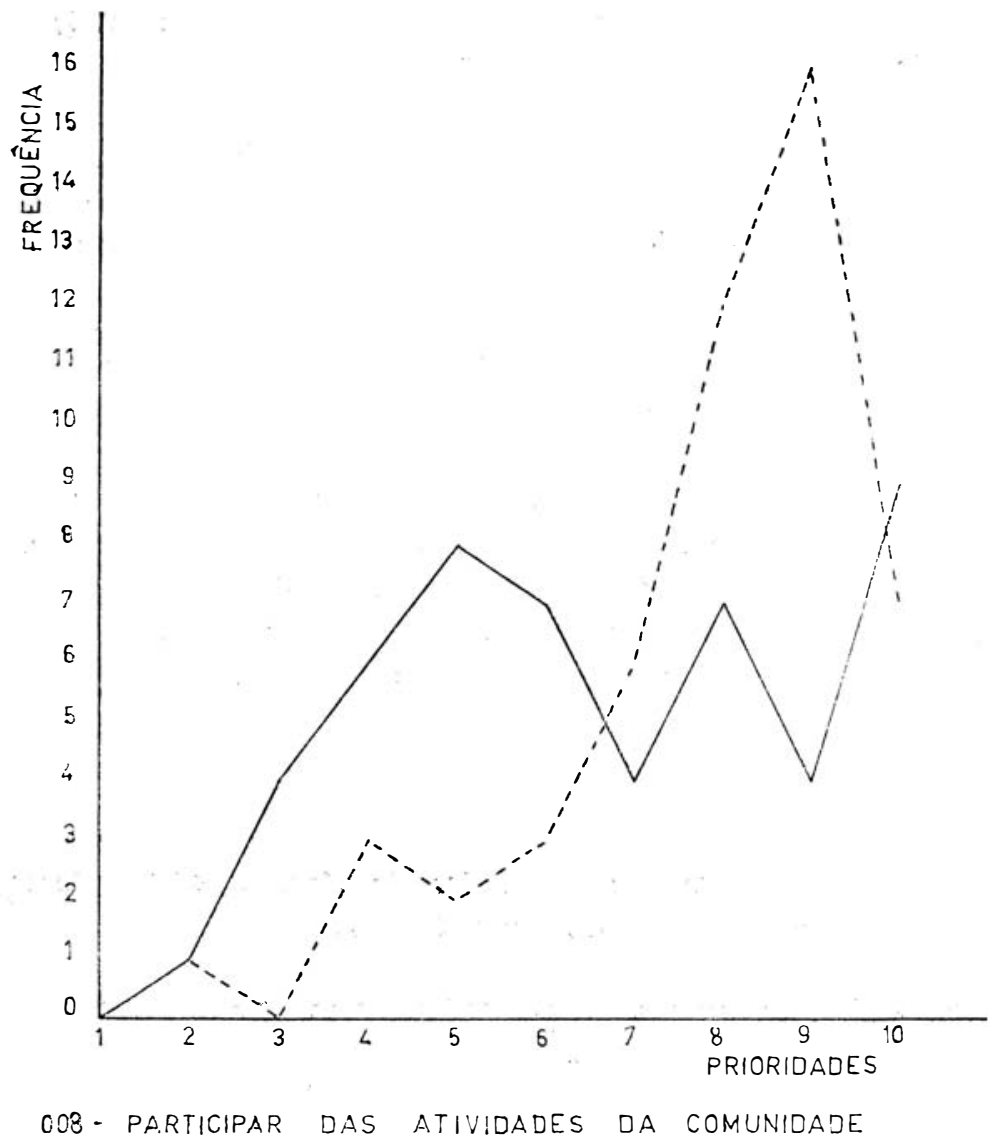

PROFESSORES

ENFERMEIROS

00-9 - "Prestar cuidados diretos demonstrando competência $e$ habilidade técnica".

Ocupou o primeiro lugar de importância pelos 2 (dois) grupos. A observação dos' dados demonstra que os professores têm nítida convicção desse comportamento como primordial para o enfermeiro, com uma concentração maciça de opiniōes no $1 .^{\circ}$ lugar de importância para este item. $42 \%$ dos enfermeiros foram coesos para ciemonstrar o $1 .^{\circ}$ lugar de importância para este comportamento. Embora fosse significativo este lugar de importância para os dois 
grupcs, foi muito mais convincente e coesa, segundo os dados, a opinião dos professores. Isto pode significar que os objetivos dos

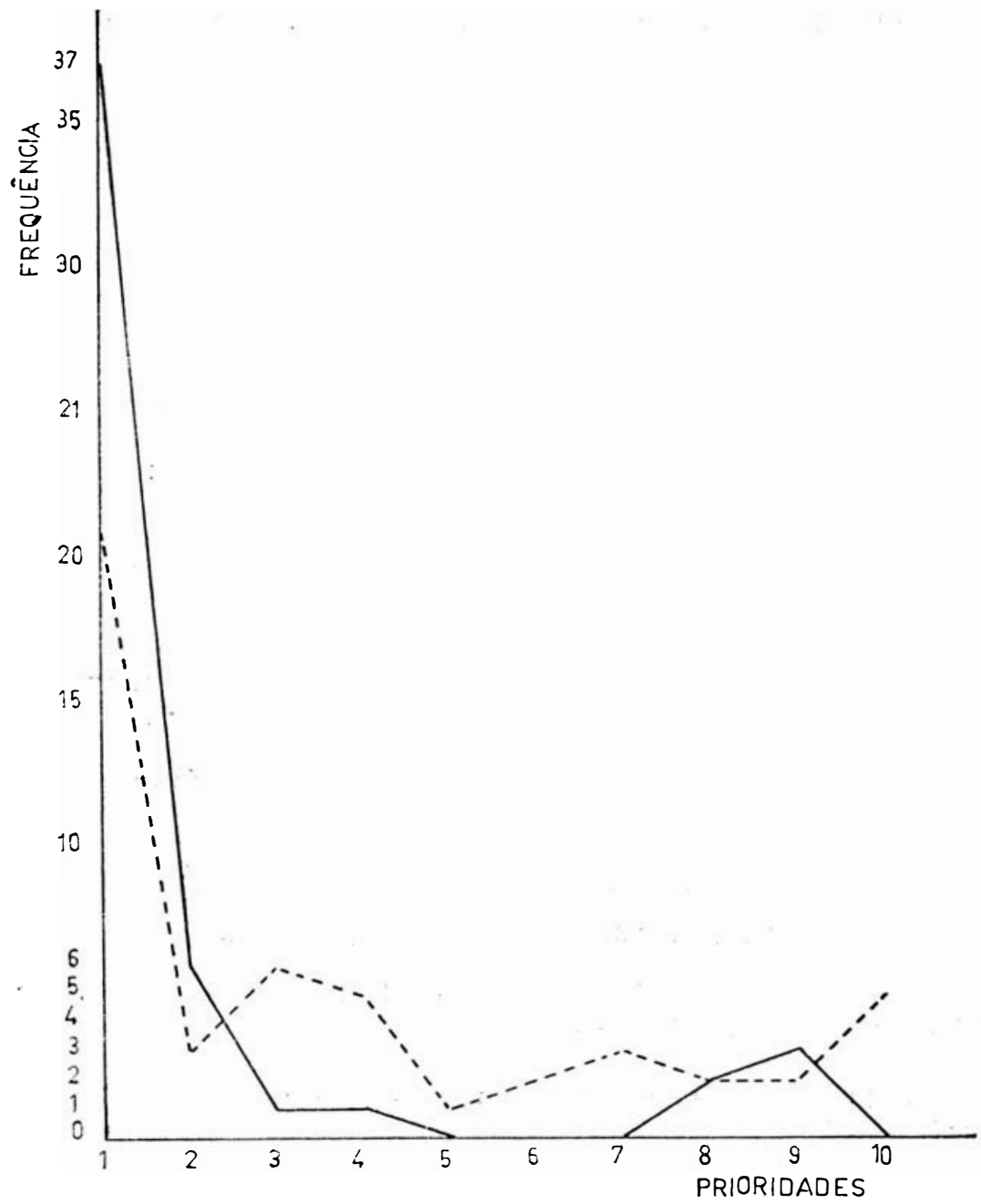

OO9- PRESTAR CUIDADOS DIRETOS A PACIENTES DEMONStRANDO COMPETÊNCIA E habILIDADE TÉCNICA 
Programas de Graduação em Enfermagem nas Escolas estão realmente voltados para o ensino do cuidado direto ao paciente.

A média ponderada apontou este objetivo como prioritário, tanto para o grupo de enfermeiros como para o de professores.

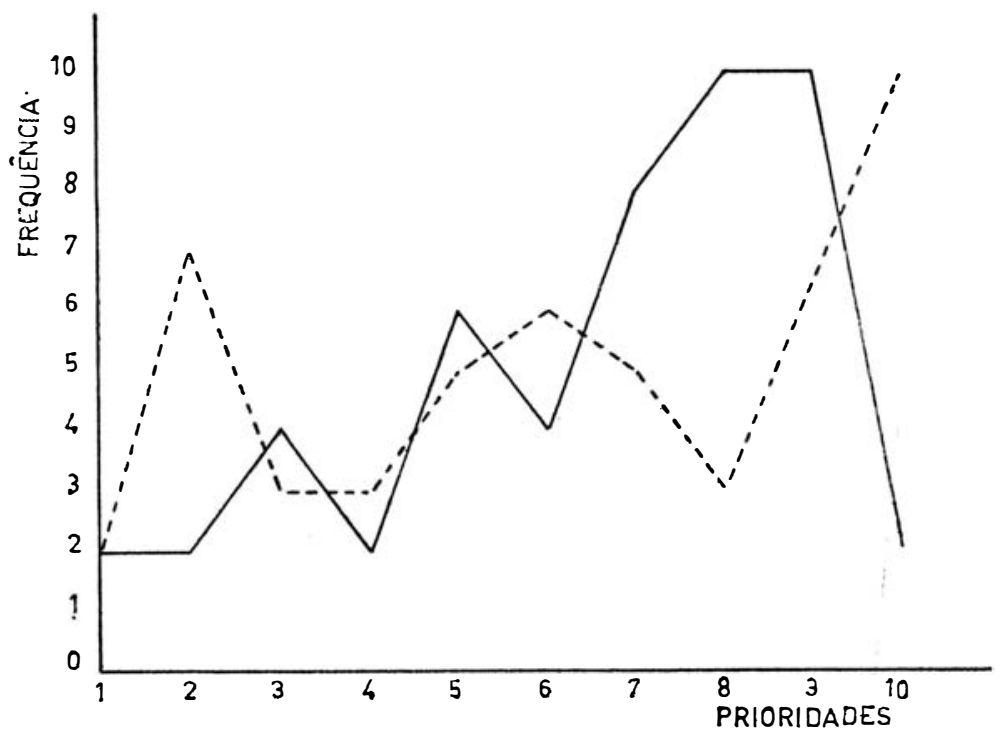

010- EfETUAR tREINAMENTO DE PESSOAL DE ENFERMAGEM

\section{PROFESSORES}

ENFERMEIROS

00-10 - Planejar, executar e avaliar programas de treinamento dQ pessoal de enfermagem".

Os professores mostraram-se mais coesos em suas respostas, porém, ambos os grupos, consideradas as médias, colocaram este comportamento como dos menos importantes, situando-o na ordem de prioridade 8 (oito), considerados os 9 (nove) outros comportamentos.

\section{$\mathrm{V}$ - CONCLUSAO}

Os comportamentos flinais desejáveis do aluno, ao término do Curso de Graduação, são os mesmos, tanto na opinião dos professores de enfermagem como dos enfermeiros. Este resultado favorece 
em grande parte o encontro de opiniões entre ambos os grupos facilitando a atuação dos mesmos quanto aos propósitos do ensino de enfermagem, e quanto à seleção e orientação das experiências de campo de prática. Este achado vem desfazer falácias quanto a possível dissidência sobre "o que o enfermeiro deve saber fazer". Contudo, ainda que haja unanimidade de opiniões quanto "o que o enfermeiro deve saber fazer ao final do curso de graduação", há diferenças nos grupos, entre a média de opiniões sobre cada um desses comportamentos finais, colocando-os em posições distintas dentro da escala de prioridades. Essa oposição de opiniões para alguns itens entre os dois grupos deve estar constituindo um certo grau de desacordo no campo de prática, e em última análise vindo a comprometer a determinação dos objetivos operacionais do Curso de Graduação em Enfermagem que embora sejam apontados como os mesmos, tanto pelos professores como pelos enfermeiros, tornam-se, em grande parte dissidentes quanto à hierarquização dos valores a ele atribuidos. Há uma notória harmonia de opiniões entre os grupos nas áreas relativas a prestar cuidados direto ao paciente, avaliar a qualidade da assistência de enfermagem e planejar, executar e avalior programas de treinamento em serviço. Em contrapasição estão as opiniões dos grupos a respeito de administrar serviços de enfermagem e elaborar planos escritos de cuidados de enfermagem.

Logo, para os professores é a seguinte a ordem de prioridade para os dez objetivos operacionais apontados como mais importantes pelos dois grupos:

\begin{aligned} & \hline 1 Prestar cuidados diretos a pacientes \\ & 2 Elaborar planos escritos de cuidados de enfermagem. \\ & 3 Avaliar a qualidade de assistência de enfermagem. \\ & 4 Comunicar-se efetivamente como profissional. \\ & 5 $\begin{array}{l}\text { Exercitar-se na profissão de acordo com as responsa- } \\ \text { bilidades ético-legais do enfermeiro. }\end{array} \\ & 6$ Interpretar a profissão junto à equipe de saúde lide- \\ & rando a equipe de enfermagem. \\ & 7 Administrar serviço de enfermagem \\ & 8 Planejar, executar e avaliar programas de treinamen- \\ & $\mathbf{9}$ to de pessoal de enfermagem. \\ & 10 Participar de atividades de Comunidade. \\ & \hline\end{aligned}


Para os enfermeiros é a seguinte a ordem de prioridade para os dez objetivos operacionais apontados como mais importantes pelos dois grupos:

\section{Prioridades}

Comportamento final

1 Prestar cuidados diretos a paciente.

2 Administrar serviços de enfermagem.

3 Avaliar a qualidade da assistência de enfermagem.

4 Exercitar-se na profissão de acordo com as responsabilidades ético-legais do enfermeiro.

5 Comunicar-se efetivamente como profissional.

6 Elaborar planos escritos de cuidados de enfermagem.

7 Interpretar a profissão junto à equipe de saúde liderando a equipe de enfermagem.

8 Planejar, executar e avaliar programas de treinamento de pessoal de enfermagem.

9 Colaborar em pesquisas na área da saúde.

10 Participar de atividades da Comunidade.

\section{VII - RECOMENDAÇOES}

Face a conclusão encontrada por este estudo pode-se chegar às recomendações que se seguem:

- Que professores de enfermagem e enfermeiros de serviços, reunam-se com o fim de identificar as causas das diferenças existentes na colocação da ordem de prioridade para alguns itens;

- Que a avaliação do desenvolvimento dos programas de ensino no campo de prática bem como a correspondente reformulação dos mesmos em termos de objetivos operacionais 
seja feita por todo o corpo docente, ouvidos todos os grupos envolvidos na formação do educando;

- que professores de enilermagem e enfermeiros procurem conjugar seus esforços no sentido de desempenharem os seus papéis de educadores, especialmente no campo de prática, no desenvolvimento dos programas de ensino e assistência de enfermagem;

- Que outras pesquisas sejam realizadas com o fim de apurar as causas dessas dissidências quanto à hierarquização dos comportamentos a serem incorporados no recém-graduado e estabelecer que objetivos devem ser mais destacados que outros;

- Que as Escolas de Enfermagem, ao formularem os objetivos operacionais dos ṕrogramas de ensino do curso de graduação em Enfermagem em conta os 10 (dez) apontados como mais importantes pelos grupos representados neste estudo. 


\begin{tabular}{llllllll}
\hline Atributos & Individuais & \multicolumn{2}{c}{ eruiessores } & Enrermeiros & \multicolumn{2}{c}{ Total } \\
\hline & Numero & $\%$ & Número & $\%$ & Número & $\%$
\end{tabular}

1. Escola em que se graduou

$\begin{array}{rrrrrrr}\text { ( A ) } & 4 & 8 & 12 & 24 & 16 & 16 \\ \text { ( B ) } & 33 & 66 & 16 & 32 & 49 & 59 \\ \text { ( C ) } & 3 & 6 & 6 & 12 & 9 & 9 \\ \text { ( D ) } & 10 & 20 & 16 & 32 & 26 & 26\end{array}$

2. Graduada há quantos

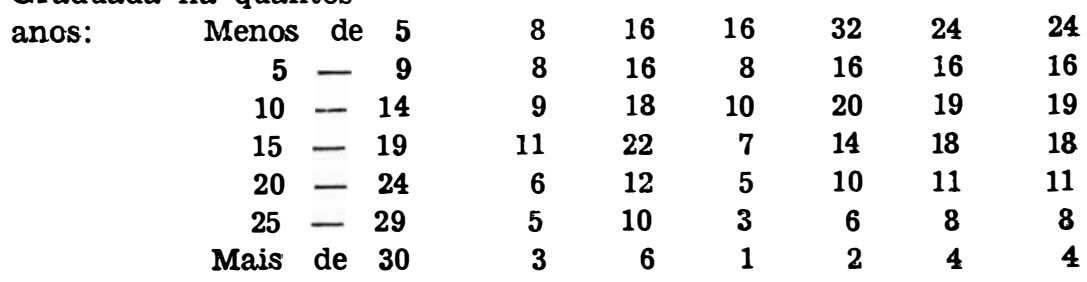

3. Tempo que exerce a

\begin{tabular}{|c|c|c|c|c|c|c|c|c|}
\hline função: Menos & de & $\mathbf{5}$ & 17 & 34 & 19 & 38 & 36 & 36 \\
\hline 5 & - & 9 & 14 & 28 & $\mathbf{9}$ & 18 & 23 & 23 \\
\hline 10 & - & 14 & 9 & 18 & 8 & 16 & 17 & 17 \\
\hline 15 & - & 19 & 4 & 8 & 7 & 14 & 11 & 11 \\
\hline 20 & - & 24 & 2 & 4 & 5 & 10 & 7 & $\mathbf{7}$ \\
\hline 25 & - & 29 & 2 & 4 & 1 & 2 & 3 & 3 \\
\hline Mais & de & 30 & 2 & 4 & 1 & 2 & 3 & 3 \\
\hline
\end{tabular}

4. Instituição em que trabalha:

$\begin{array}{rcrrrrrr}\text { - Escola } & \text { (A) } & 15 & 30 & - & - & - & - \\ & \text { ( B ) } & 30 & 60 & - & - & - & - \\ & \text { ( C ) } & 5 & 10 & - & - & - & - \\ \text { Serviço } & \text { I } & - & - & 5 & 10 & - & - \\ & \text { II } & - & - & 16 & 32 & - & - \\ & \text { III } & - & - & 13 & 26 & - & - \\ & \text { IV } & - & - & 3 & 6 & - & - \\ & \text { V } & - & - & 8 & 16 & - & - \\ & \text { VI } & - & - & 1 & 2 & - & - \\ & \text { VII } & - & - & 4 & 8 & - & -\end{array}$

5. Idade Cronológica em

\begin{tabular}{|c|c|c|c|c|c|c|c|c|c|}
\hline \multirow[t]{8}{*}{ anos: } & 20 & - & 25 & 1 & 2 & 6 & 12 & 7 & 7 \\
\hline & 26 & - & 30 & 8 & $1 \epsilon$ & 10 & 20 & 18 & 18 \\
\hline & 31 & -.. & 35 & 9 & 18 & 6 & 12 & 15 & 15 \\
\hline & 36 & - & 40 & 9 & 18 & 15 & 30 & 24 & 24 \\
\hline & 41 & - & 45 & 13 & 26 & 4 & 8 & 17 & 17 \\
\hline & 46 & - & 50 & 3 & 6 & 5 & 10 & 8 & 8 \\
\hline & 51 & - & 55 & 6 & 12 & 2 & 4 & 8 & 8 \\
\hline & Mais & de & 56 & 1 & 2 & 2 & 4 & 3 & 3 \\
\hline
\end{tabular}


TABELA II - LISTA PRELIMINAR DE ITENS APONTADOS PELOS 2 (DOIS) GRUPOS COMO COMPORTAMENTOS ESPERADOS DO ENFERMEIRO

Itens que envolvem alguns comportamen- Profes- Enfertos esperados do enfermeiro sores meiro Total

1. Adequar a técnica à realidade

S. Saúde

2. Administrar unidade de enfermagem

3. Avaliar a Assistência de Enfermagem

4. Atitude profissional

5. Aprimoramento contínuo

6. Ajustamento profisional

7. Controlar e coordenar a Equipe de Enfermagem no cuidado direto ao Paciente

8. Comunicar-se efetivamente

9. Conhecer a realidade de saúde do pais

10. Delegar tarefas

11. Divulgar a Enfermagem

12. Exercer a profissão dentro dos padrões éticos legais de enfermagem

13. Espírito de classe

14. Habilidades técnicas

15. Integrar-se na equipe de saúde

16. Identificar problemas de enfermagem

17. Interesse profisional

18. Liderança na Equipe de Enfermagem

19. Planejar cuidados (planos escritos)

20. Prestas cuidados diretos pacientefamília

21. Promover auto-desenvolvimento

22. Pesquisa

$\begin{array}{rrr}1 & 6 & 7 \\ 6 & 7 & 13 \\ 5 & 2 & 7 \\ 2 & 6 & 8 \\ 3 & 2 & 5 \\ 0 & 2 & 2\end{array}$

23. Participar na resolução de problemas de saúde

24. Treinamento em serviço

25. Utilizar os recursos da comunidade

$\begin{array}{rrr}10 & 1 & 11 \\ 3 & 8 & 11 \\ 0 & 9 & 9 \\ 1 & 0 & 1 \\ 0 & 2 & 2\end{array}$

$\begin{array}{lll}0 & 8 & 8\end{array}$

2002

$\begin{array}{lll}2 & 10 & 12\end{array}$

$5 \quad 5 \quad 10$

$5 \quad 0 \quad 5$

$0 \quad 11$

$8 \quad 1 \quad 9$

$11 \quad 2 \quad 13$

$\begin{array}{rr}4 & 22 \\ 0 & 2 \\ 3 & 4\end{array}$

$\begin{array}{lll}0 & 2\end{array}$

$\begin{array}{lll}4 & 5 & 9\end{array}$

$\begin{array}{lll}0 & 3 & 3\end{array}$


TABELA III - FORMULÁRIO CONTENDO DEZ ITENS ARROLADOS EM ORDEM ALFABÉTICA EXTRAÍDOS DOS COMPORTAMENTOS APONTADOS PELOS DOIS GRUPOS COMO OS MAIS IMPORTANTES PARA O DESEMPENHO DO ENFERMEIRO

\section{Objetivos operacionais \\ ordem alfabética}

Ao término do curso de graduação, o enfermeiro deve saber fazer
I.ugar de importância 
TABELA IV - IMPORTANCIA ATRIBUHDA AO ITEM: OO-1 “ADMINISTRAR SERVIÇOS DE ENFERMAGEM"

\begin{tabular}{|c|c|c|c|c|c|}
\hline \multirow{2}{*}{$\begin{array}{c}\text { Lugar de } \\
\text { importância }\end{array}$} & \multirow{2}{*}{$\begin{array}{l}\text { Peso atribuído } \\
\text { a cada lugar } \\
\text { de importância }\end{array}$} & \multicolumn{2}{|c|}{ Professores } & \multicolumn{2}{|c|}{ Enfermeiros } \\
\hline & & N.o & $\%$ & N..$^{\circ}$ & $\%$ \\
\hline 1 & 10 & 0 & 0 & 11 & 22 \\
\hline 2 & 9 & 2 & 4 & 10 & 20 \\
\hline 3 & 8 & 5 & 10 & 5 & 10 \\
\hline 4 & 7 & 6 & 12 & 6 & 12 \\
\hline 5 & 6 & 9 & 18 & 7 & 14 \\
\hline 6 & 5 & 5 & 8 & 2 & 4 \\
\hline 7 & 4 & 6 & 12 & 3 & 6 \\
\hline 8 & 3 & 4 & 8 & 2 & 4 \\
\hline 9 & 2 & 1 & 2 & 1 & 2 \\
\hline 10 & 1 & 13 & 26 & 3 & $B$ \\
\hline TOTAL & 55 & 50 & 100 & 50 & 100 \\
\hline
\end{tabular}

TABELA $\mathbf{v}$ - IMPORTANCIA ATRIBUIDA AO ITEM: OO-2 "AVALIAR A QUALIDADE DA ASSISTBNCIA DE ENFERMAGEM"

\begin{tabular}{ccrrrr}
\hline & Peso atribuido & & & \\
Lugar de & $\begin{array}{c}\text { a cada lugar } \\
\text { importância }\end{array}$ & \multicolumn{2}{c}{ Professores } & \multicolumn{2}{c}{ Enfermeiros } \\
& de importância & N.0 & $\%$ & N. $^{0}$ & $\%$ \\
\hline 1 & 10 & 1 & 2 & 2 & 4 \\
2 & 9 & 5 & 10 & 10 & 20 \\
3 & 8 & 7 & 14 & 10 & 20 \\
4 & 7 & 12 & 24 & 10 & 20 \\
5 & 6 & 3 & 6 & 7 & 14 \\
6 & 5 & 7 & 14 & 3 & 6 \\
7 & 4 & 6 & 12 & 3 & 6 \\
8 & 3 & 5 & 10 & 2 & 4 \\
9 & 2 & 4 & 8 & 1 & 2 \\
10 & 1 & 0 & 0 & 2 & 4 \\
\hline TOTAL & 55 & 50 & 100 & 50 & 100 \\
\hline
\end{tabular}




\section{TABELA VI - IMPORTÂNCIA ATRIBUIDA AO ITEM: Oo-3 "COLABORAR EM PESQUISAS NA ÁREA DA SAÚDE"}

\begin{tabular}{cccccr}
\hline & \multicolumn{2}{c}{ Peso atribuído } & \multicolumn{3}{c}{} \\
$\begin{array}{c}\text { Lugar de } \\
\text { importância }\end{array}$ & $\begin{array}{c}\text { a cada lugar } \\
\text { de importância }\end{array}$ & \multicolumn{2}{c}{ Professores } & \multicolumn{2}{c}{ Enfermeiros } \\
& & $\%$ & N.o & $\%$ \\
\hline 1 & 10 & 0 & 0 & 0 & 0 \\
2 & 9 & 0 & 0 & 2 & 4 \\
3 & 8 & 2 & 4 & 5 & 10 \\
4 & 7 & 2 & 4 & 5 & 10 \\
5 & 6 & 5 & 10 & 2 & 4 \\
6 & 5 & 6 & 12 & 2 & 4 \\
7 & 4 & 8 & 16 & 7 & 14 \\
8 & 3 & 6 & 12 & 7 & 14 \\
9 & 2 & 6 & 12 & 7 & 14 \\
10 & 1 & 15 & 30 & 13 & 26 \\
\hline TOTAL & 55 & 50 & 100 & 50 & 100 \\
\hline
\end{tabular}

TABELA VII - IMPORTÂNCIA ATRIBUIDA AO ITEM: OO-4 "COMUNICAR-SE EFETIVAMENTE COMO PROFISSIONAL"

\begin{tabular}{ccrrrr}
\hline $\begin{array}{c}\text { Lugar de } \\
\text { importância }\end{array}$ & $\begin{array}{c}\text { Peso atribuído } \\
\text { a cada lugar } \\
\text { de importância }\end{array}$ & \multicolumn{2}{c}{$\begin{array}{c}\text { Professores } \\
\text { N.0 }\end{array}$} & \multicolumn{2}{c}{ Enfermeiros } \\
N.0 & \% \\
\hline 1 & 10 & 2 & 4 & 3 & 6 \\
2 & 9 & 2 & 4 & 6 & 12 \\
3 & 8 & 8 & 16 & 7 & 14 \\
4 & 7 & 3 & 6 & 7 & 14 \\
5 & 6 & 8 & 16 & 3 & 6 \\
6 & 5 & 10 & 20 & 8 & 16 \\
7 & 4 & 4 & 8 & 4 & 8 \\
8 & 3 & 3 & 6 & 4 & 8 \\
9 & 2 & 5 & 10 & 4 & 8 \\
10 & 1 & 5 & 10 & 4 & 8 \\
\hline TOTAL & 55 & 50 & 100 & 50 & 100 \\
\hline
\end{tabular}


TABELA VHI - IMPORTÂNCIA ATRIBUÍDA AO ITEM:

Oo-5 "ELABORAR PLANOS ESCRITOS DE CUIDADOS DE ENFERMAGEM"

\begin{tabular}{|c|c|c|c|c|c|}
\hline \multirow{2}{*}{$\begin{array}{c}\text { Lugar de } \\
\text { importância }\end{array}$} & \multirow{2}{*}{$\begin{array}{l}\text { Peso atribuído } \\
\text { a cada lugar } \\
\text { de importância }\end{array}$} & \multicolumn{2}{|c|}{ Professores } & \multicolumn{2}{|c|}{ Enfermeiros } \\
\hline & & N.o & $\%$ & N.o & $\%$ \\
\hline 1 & 10 & 3 & 6 & 1 & 2 \\
\hline 2 & 9 & 21 & 42 & 3 & 6 \\
\hline 3 & 8 & 10 & 20 & 5 & 10 \\
\hline 4 & 7 & 4 & 8 & 2 & 4 \\
\hline 5 & 6 & 5 & 10 & 11 & 22 \\
\hline 6 & 5 & 3 & 6 & 13 & 26 \\
\hline 7 & 4 & 1 & 2 & 3 & 6 \\
\hline 8 & 3 & 2 & 4 & 7 & 14 \\
\hline 9 & 2 & 1 & 2 & 2 & 4 \\
\hline 10 & 1 & 0 & $\mathbf{0}$ & 3 & 6 \\
\hline TOTAL & 55 & 50 & 100 & 50 & 100 \\
\hline
\end{tabular}

TABELA IX - IMPORTÂNCIA ATRIBUHDA AO ITEM:

OO-6 "EXERCITAR-SE NA PROFISSÃO DE ACORDO COM AS RESPONSABHIDADES ÉTICO-

LEGAIS DA ENFERMAGEM"

\begin{tabular}{|c|c|c|c|c|c|}
\hline \multirow{2}{*}{$\begin{array}{c}\text { Lugar de } \\
\text { importância }\end{array}$} & \multirow{2}{*}{$\begin{array}{l}\text { Peso atribuído } \\
\text { a cada lugar } \\
\text { de importância }\end{array}$} & \multicolumn{2}{|c|}{ Professores } & \multicolumn{2}{|c|}{ Enfermeiros } \\
\hline & & N. ${ }^{\circ}$ & $\%$ & N.o & $\%$ \\
\hline 1 & 10 & 4 & 8 & 4 & 8 \\
\hline 2 & 9 & 6 & 12 & 6 & 12 \\
\hline 3 & 8 & 6 & 12 & 5 & 10 \\
\hline 4 & 7 & 5 & 10 & 6 & 12 \\
\hline 5 & 6 & 3 & 6 & 8 & 16 \\
\hline 6 & 5 & 4 & 8 & 7 & 14 \\
\hline 7 & 4 & 6 & 12 & 7 & 14 \\
\hline 8 & 3 & 6 & 12 & 4 & 8 \\
\hline 9 & 2 & 7 & 14 & 3 & 6 \\
\hline 10 & 1 & 3 & 6 & 0 & 0 \\
\hline TOTAL & 55 & 50 & 100 & 50 & 100 \\
\hline
\end{tabular}


TABELA $X$ - IMPORTANCIA ATRIBUTDA AO ITEM:

OO-y "INTERPRETAR A PROFISSÃO JUNTO A EQUIPE DE SAÚDE LIDERANDO A EQUIPE DE ENFERMAGEM"

\begin{tabular}{|c|c|c|c|c|c|}
\hline \multirow{2}{*}{$\begin{array}{l}\text { Lugar de } \\
\text { importância }\end{array}$} & \multirow{2}{*}{$\begin{array}{l}\text { Peso atribuido } \\
\text { a cada lugar } \\
\text { de importância }\end{array}$} & \multicolumn{2}{|c|}{ Professores } & \multicolumn{2}{|c|}{ Enfermeiros } \\
\hline & & N.o & $\%$ & N..$^{\circ}$ & $\%$ \\
\hline 1 & 10 & 2 & 4 & 6 & 12 \\
\hline 2 & 9 & 2 & 8 & 3 & 6 \\
\hline 3 & 8 & 4 & 8 & 4 & 8 \\
\hline 4 & 7 & 8 & 16 & 1 & 2 \\
\hline 5 & 6 & 5 & 10 & 5 & 10 \\
\hline 6 & 5 & 6 & 12 & 3 & 6 \\
\hline 7 & 4 & 6 & 12 & 10 & 20 \\
\hline 8 & 3 & 6 & 12 & 7 & 16 \\
\hline 9 & 2 & 7 & 14 & 8 & 16 \\
\hline 10 & 1 & 2 & 4 & 3 & 6 \\
\hline TOTAL & 55 & 50 & 100 & 50 & 100 \\
\hline
\end{tabular}

TABFLA XI - IMPORTANCIA ATRIBUIDA AO ITEM: 00-8 "PARTICIPAR DAS ATIVIDADES DA COMUNIDADE"

\begin{tabular}{|c|c|c|c|c|c|}
\hline \multirow{2}{*}{$\begin{array}{l}\text { Lugar de } \\
\text { importância }\end{array}$} & \multirow{2}{*}{$\begin{array}{l}\text { Peso atribuido } \\
\text { a cada lugar } \\
\text { de importância }\end{array}$} & \multicolumn{2}{|c|}{ Professores } & \multicolumn{2}{|c|}{ Enfermeiros } \\
\hline & & N.o & $\%$ & N.o & $\%$ \\
\hline 1 & 10 & 0 & 0 & 0 & 0 \\
\hline 2 & 9 & 1 & 2 & 1 & 2 \\
\hline 3 & 8 & 4 & 8 & 0 & 0 \\
\hline 4 & 7 & 6 & 12 & 3 & 6 \\
\hline 5 & 6 & 8 & 16 & 2 & 4 \\
\hline 6 & 5 & 7 & 14 & & 6 \\
\hline 7 & 4 & 4 & 8 & 6 & 12 \\
\hline 8 & 3 & 7 & 14 & 12 & 24 \\
\hline$\theta$ & 2 & 4 & 8 & 16 & 32 \\
\hline 10 & 1 & 9 & 18 & 7 & 14 \\
\hline TOTAL & 55 & 50 & 100 & 50 & 100 \\
\hline
\end{tabular}


TABELA XII - IMPORTACIA ATRIBUADA AO ITEM:

OO-9 "PRESTAR CUIDADOS DE ENFERMAGEM A PACIENTES DEMONSTRANDO COMPETENCIA E HABILIDADE TECNICA"

\begin{tabular}{|c|c|c|c|c|c|}
\hline \multirow{2}{*}{$\begin{array}{c}\text { Lugar de } \\
\text { importância }\end{array}$} & \multirow{2}{*}{$\begin{array}{l}\text { Peso atribuído } \\
\text { a cada lugar } \\
\text { de importância }\end{array}$} & \multicolumn{2}{|c|}{ Professores } & \multicolumn{2}{|c|}{ Enfermeiros } \\
\hline & & N.o & $\%$ & N.o & $\%$ \\
\hline 1 & 10 & 37 & 74 & 21 & 42 \\
\hline 2 & 9 & 6 & 12 & 3 & 6 \\
\hline 3 & 8 & 1 & 2 & 6 & 12 \\
\hline 4 & 7 & 1 & 2 & 5 & 10 \\
\hline 5 & 6 & $\mathbf{0}$ & $\mathbf{0}$ & 1 & 2 \\
\hline 6 & 5 & $\mathbf{0}$ & $\mathbf{0}$ & 2 & 4 \\
\hline 7 & 4 & 0 & $\mathbf{0}$ & 3 & 6 \\
\hline 8 & 3 & 2 & 4 & 2 & 4 \\
\hline 9 & 2 & 3 & 6 & 2 & 4 \\
\hline 10 & 1 & $\mathbf{0}$ & $\mathbf{0}$ & 5 & 10 \\
\hline TOTAL & 55 & 50 & 100 & 50 & 100 \\
\hline
\end{tabular}

TABELA XIII - IMPORTANCIA ATRIBUIDA AO ITEM:

OO-10 "PLANEJAR, EXECUTAR E AVALIAR PROGRAMAS DE TREINAMENTO de PESSOAL DE ENFERMAGEM"

\begin{tabular}{|c|c|c|c|c|c|}
\hline \multirow{2}{*}{$\begin{array}{l}\text { Lugar de } \\
\text { importância }\end{array}$} & \multirow{2}{*}{$\begin{array}{l}\text { Peso atribuido } \\
\text { a cada lugar } \\
\text { de importância }\end{array}$} & \multicolumn{2}{|c|}{ Professores } & \multicolumn{2}{|c|}{ Enfermeiros } \\
\hline & & $\mathbf{N}^{\circ}$ & $\%$ & N.o & $\%$ \\
\hline 1 & 10 & 2 & 4 & 2 & 4 \\
\hline 2 & 9 & 2 & 4 & 7 & 14 \\
\hline 3 & 8 & 4 & 8 & 3 & 6 \\
\hline 4 & 7 & 2 & 4 & 3 & 6 \\
\hline 5 & 6 & 6 & 12 & 5 & 10 \\
\hline 6 & 5 & 4 & 8 & 6 & 12 \\
\hline 7 & 4 & 8 & 16 & 5 & 10 \\
\hline 8 & 3 & 10 & 20 & 3 & 6 \\
\hline 9 & 2 & 10 & 20 & 6 & 12 \\
\hline 10 & 1 & 2 & 4 & 10 & 20 \\
\hline TOTAL & 55 & 50 & 100 & 50 & 100 \\
\hline
\end{tabular}




\section{TABELA XIV - OPINIÕES DE PROFESORES E DE ENFERMEI- ROSi APÓS O CÁlCULO da MÉdia PONDERAda PARA CADA ITEM, DE ACORDO COM O LUGAR DE IMPORTÂNCIA ATRIBUIDA PELOS GRUPOS}

Item correspondente a comportatos: ordem apresentada no formulário (alfabética)
Média ponderada das opinióes * Professores
Enfermeiros

$\begin{array}{lll}\text { Oo-1 } & 4.09 & 6.49 \\ \text { Oo-2 } & 5.36 & 6.16 \\ \text { Oo-3 } & 3.03 & 3.47 \\ \text { Oo-4 } & 5.03 & 5.21 \\ \text { Oo-5 } & 6.98 & 4.76 \\ \text { Oo-6 } & 4.98 & 5.54 \\ \text { Oo-7 } & 4.76 & 4.56 \\ \text { Oc-8 } & 4.00 & 2.83 \\ \text { Oo-9 } & 8.20 & 6.60 \\ \text { Oo-10 } & 4.07 & 4.34\end{array}$

* Os pesos foram estabelecidos de acordo com o lugar de importância (ou ordem de prioridade) atribuído pelo respondente para cada item: desse modo para cada item foi solicitada uma ordem de prioridade (de 1 a 10) e a cada lugar de importância atribuído correspondia 1 peso, equivalente ao inverso dessa ordem.

Ordem de prioridade atribuida

Peso correspondente

625

7 7

8 3


TABELA XV - ORDEM DE PRIORIDADE DOS ITENS SUGERIDA PELA MÉdA DE OPINIŌES DOS GRUPOS RESPONDENTES

\begin{tabular}{|c|c|c|c|c|}
\hline \multicolumn{2}{|c|}{$\begin{array}{l}\text { Médias ponedradas em } \\
\text { ordem decrescente }\end{array}$} & \multicolumn{3}{|c|}{$\begin{array}{l}\text { Lugar de importância sugerido pela } \\
\text { média ponderada em ordem decrescente }\end{array}$} \\
\hline Professores & Enfermeiros & Prioridade & Professores & Enfermeiros \\
\hline 8,20 & 6,60 & 1 & O०-9 & $00-9$ \\
\hline 6,90 & 6,49 & 2 & Oo-5 & Oo-1 \\
\hline 5,36 & 6,16 & 3 & Oo-2 & Oo-2 \\
\hline 5,03 & 5,54 & 4 & $00-4$ & $00-6$ \\
\hline 4,98 & 5,21 & 5 & $00-6$ & $00-4$ \\
\hline 4,76 & 4,76 & 6 & $00-7$ & Oo-5 \\
\hline 4,09 & 4,56 & 7 & Oo-1 & $00-7$ \\
\hline 4,07 & 4,34 & 8 & $00-10$ & $00-10$ \\
\hline 4,00 & 3,47 & 9 & O0-8 & 0o-3 \\
\hline 3,03 & 2,83 & 10 & Oo-3 & $00-8$ \\
\hline
\end{tabular}


TABELA XVI - RELAÇAO ENTRE OS ITENS APRESENTADOS EM ORDEM ALFABETICA E A ORDEM DE PRIORIDADE SUGERIDA EM CADA GRUPO

Itens apresentados

no formulário

(Ordem alfabética)
Ordem de prioridade sugerida por

Professores Enfermeiros

Oo-1 Administrar Serviços de Enfermagem

7

Oo-2 Avaliar a qualidade da Assistência de Enfermagem 3 3

Oo-3 Colaborar em Pesquisas na Area da Saúde

Oo-4 Comunicar-se efetivamente como profissional

O0-5 Elaborar planos escritos de cuidados de enfermagem

O0-6 Exercitar-se na profissão de acordo com as responsabilidades éticolegais

Oo-7 Interpretar a profissão junto à equipe de saúde liderando a equipe de enfermagem

6 7

Oo-8 Participar de atividades da Comunidade

9 10

Oo-9 Prestar cuidados diretos a pacientes demonstrando competêncla e habilidade técnica

1 1

Oo-10 Planejar, executar e avaliar programas de treinamento de pessoal de enfermagem 
VIII - BIBLIOGRAFIA

ALCANTARA, Glete de - "Revisão do Currículo Princípios Gerais" RBEn; 1: 51-59, 1960.

RLOOM, Benjamin S. - "Toxionomy of educational objectives handbook, cognitive domain". New York, McKay Co, 1960.

BROW, Amy Frances - “Curriculum para Escuelas de Enfermagem" C.R.T.A. México, 1. Ediçăo, 1964.

CARvalHo, Amália Correa de - Finalidades e Objetivos do Curso de Enfermagem"'. R.E.E.U.S.P., 1 (1), 1967.

COE, Charlotte R. - "The Relative Importance of Selected Educational Objectives in Nursing"'. Nursing Research, 2 (16): 141-145, 1967.

ESTEVES, Oyara R. - “Objetivos Educacionais" Fleury Esteves Arte y Ind. Ed. Rio de Janeiro, 1968.

ESTEVES, Oyara P. - “Testes, medidas e Avaliação". Fleury Esteves Arte y Ind. Ed. Rio de Janeiro, 1970.

FIVARS, Grace; GOSNEHL, Doris - Nursing Evaluation: The problem and the Process. The critical incident technique". The Macmillan Company. New York, 1969.

GARNE, R. M. - “Como se realiza a aprendizagem”. Ao Livro Técnico. Rio de Janeiro, 1971.

LOURENÇO FILHO, M. B. - et allü - Três Ensaios sobre Avaliaçäo Educacional Fundação Getúlio Vargas. Rio de Janeiro, 1968.

OPAS/OMS: - Enseñanza de Enfermeria a nivel universitário. Informe Cientifico, 259 (11-12), 1971

RIBEIRO, C. M. - "Novas tendências no ensino e na prática de enfermagem" R.E.E.U. S.P., 4 (1 - 2): 21-39, 1970.

“Atividades de Enfemagem". R.E.E.U.S.P., 1 (8-9), 1971.

RIVGRA, Simone F. - "Impartância e papel dos Objetivos do Ensino no trabalho docente" RBEn, 1: 60-67, 1961. 